\title{
Performed Activity Repetition Number
}

National Cancer Institute

\section{Source}

National Cancer Institute. Performed Activity Repetition Number. NCI Thesaurus. Code C93899.

An integer that identifies the particular occurrence of a repeating activity. The first repetition is defined as ' 1 '. 